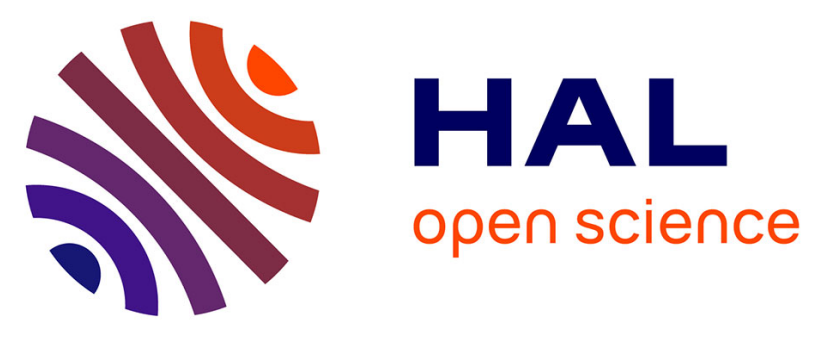

\title{
Risk factors for sporadic Yersinia enterocolitica infections: a systematic review and meta-analysis
}

Laurent Guillier, Philippe Fravalo, Alexandre Leclercq, Pauline Kooh, Anne Thébault, Vasco Cadavez, Ursula Gonzales-Barron

\section{- To cite this version:}

Laurent Guillier, Philippe Fravalo, Alexandre Leclercq, Pauline Kooh, Anne Thébault, et al.. Risk factors for sporadic Yersinia enterocolitica infections: a systematic review and meta-analysis. Microbial Risk Analysis, 2020, pp.100141. 10.1016/j.mran.2020.100141 . pasteur-03040641

\section{HAL Id: pasteur-03040641 \\ https://hal-pasteur.archives-ouvertes.fr/pasteur-03040641}

Submitted on 4 Dec 2020

HAL is a multi-disciplinary open access archive for the deposit and dissemination of scientific research documents, whether they are published or not. The documents may come from teaching and research institutions in France or abroad, or from public or private research centers.
L'archive ouverte pluridisciplinaire $\mathbf{H A L}$, est destinée au dépôt et à la diffusion de documents scientifiques de niveau recherche, publiés ou non, émanant des établissements d'enseignement et de recherche français ou étrangers, des laboratoires publics ou privés.

\section{(ㅇ)(1) $\$$}

Distributed under a Creative Commons Attribution - NonCommercial - NoDerivatives| 4.0 


\section{Journal Pre-proof}

Risk factors for sporadic Yersinia enterocolitica infections: a systematic review and meta-analysis

Laurent Guillier, Philippe Fravalo, Alexandre Leclercq , Anne Thébaut, Pauline Kooh, Vasco Cadavez, Ursula Gonzales-Barron

PII:

DOI:

Reference:

To appear in:

Received date:

Revised date:

Accepted date:
S2352-3522(20)30047-5

https://doi.org/10.1016/j.mran.2020.100141

MRAN 100141

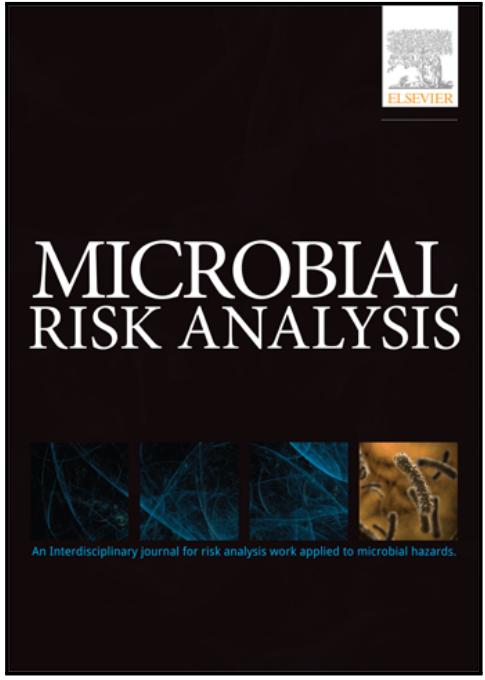

Microbial Risk Analysis

Please cite this article as: Laurent Guillier, Philippe Fravalo, Alexandre Leclercq, Anne Thébaut, Pauline Kooh, Vasco Cadavez, Ursula Gonzales-Barron, Risk factors for sporadic Yersinia enterocolitica infections: a systematic review and meta-analysis, Microbial Risk Analysis (2020), doi: https://doi.org/10.1016/j.mran.2020.100141

This is a PDF file of an article that has undergone enhancements after acceptance, such as the addition of a cover page and metadata, and formatting for readability, but it is not yet the definitive version of record. This version will undergo additional copyediting, typesetting and review before it is published in its final form, but we are providing this version to give early visibility of the article. Please note that, during the production process, errors may be discovered which could affect the content, and all legal disclaimers that apply to the journal pertain.

(C) 2020 Elsevier B.V. All rights reserved. 
Risk factors for sporadic Yersinia enterocolitica infections: a systematic review and meta-analysis

\section{Authors}

Laurent Guillier ${ }^{1}$, Philippe Fravalo ${ }^{2}$, Alexandre Leclercq ${ }^{3}$, Anne Thébaut ${ }^{1}$, Pauline Kooh ${ }^{1}$, Vasco Cadavez ${ }^{4}$, Ursula Gonzales-Barron ${ }^{4}$

\section{Affiliations}

${ }^{1}$ Risk Assessment Department, French Agency for Food, Environmental and Occupational Health \& Safety (Anses), 14 rue Pierre et Marie Curie Maisons-Alfort, France. laurent.guillier@anses.fr

2 Veterinary School, University of Montreal, 3200 Sicotte Saint-Hyacinthe J2S7C6 QC Canada. 33+(0) 695644798. Present address: Cnam, 2 Rue Camille Guérin, 22400 Ploufragan, France.philippe.fravalo@lecnam.net

${ }^{3}$ Institut Pasteur, National Reference Centre and WHO Collaborating Centre Listeria, Paris, France; Institut Pasteur, Biology of Infection Unit, Paris, France. alexlec@pasteur.fr

${ }^{4}$ Centro de Investigação de Montanha (CIMO), Instituto Politécnico de Bragança, Campus de Santa Apolónia, 5300-253 Bragança, Portugal; vcadavez@ipb.pt; ubarron@ipb.pt

Corresponding author: laurent.guillier@anses.fr 33+(0) 149772648

\section{Short Title}

Meta-analysis on risk factors for sporadic $Y$. enterocilitica infections 
Keywords: Research synthesis; Case-control studies; Meta-regression; Yersinia enterocolitica

\section{Abstract}

Yersinia enterocolotica is an important causative agent of diarrheal illness. A systematic review and meta-analysis of case-control studies were performed to determine the main risk factors associated with sporadic $Y$. enterocolitica infections. Suitable scientific articles published between 1987 and 2017 were identified through a systematic literature search and subject to methodological quality assessment. From each study, odds ratios (OR) were extracted or calculated, as well as study characteristics such as population type, design, type of model used and risk factor categorization. Mixed-effects meta-analytical models were adjusted by population type to appropriate data partitions. From 807 identified references, the quality assessment stage was passed by 14 case-control studies focusing on sporadic $Y$. enterocolitica infections which provided 165 ORs for meta-analysis. All studies considered $Y$. enterocolitica as the cause of sporadic infections and are mainly located in Europe.

The meta-analysis identified host-specifics factors, animal and food exposures as significant risk factors. The meta-analysis confirms the predominant role of the pig reservoir. The occupational contact with pigs and the consumption of pork meat are significantly associated with sporadic $Y$. enterocolitica infections occurrence. The consumption of raw or undercooked pork meat is also a very important risk factor. Untreated drinking water was also identified as risk factor. Further studies with other enteropathogenic Yersinia species, especially $Y$. pseudotuberculosis, and/or from other continents would help to refine conclusions of the meta-analysis of the risk factors of yersiniosis. 


\section{Highlights}

- Meta-analysis of 14 case-control studies about sporadic human yersiniosis

- Available studies focus on Y. enterocolitica and mainly from Europe

- Consumption of pork meat and untreated drinking water were the main determinant of sporadic $Y$. enterocolitica infections

- The consumption of undercooked or raw pork meat considerably increases risk levels 


\section{Introduction}

The genus Yersinia is composed of 19 species, among which two are enteropathogenic to humans (Y. enterocolitica, and Y. pseudotuberculosis) (Savin et al., 2019). Enteropathogenic Yersinia are mainly found in temperate or cold regions, such as Central and Northern Europe, New-Zealand and North America. Strains of Yersinia are ubiquitous and occur in soil, surface water, food and in the digestive tract of various animal species (Le Guern et al., 2016).

$Y$. enterocolitica is the main species in the genus associated with yersiniosis, which can be defined as a mild-moderate self-limiting gastroenteritis (Galindo et al., 2011). $Y$. enterocolitica is subdivided into 6 biotypes $(1 \mathrm{~A} / 1 \mathrm{~B}, 2,3,4,5)$ based on biochemical tests and more than 70 serotypes (Le Guern et al., 2016; Wauters, 1987). Y. enterocolitica infection is usually characterized by diarrhea, fever and abdominal pain (Savin et al., 2008). Patients do not always present all three symptoms. Complications such as reactive arthritis or, more rarely, sepsis can also be observed in individuals (Hoffmann and Scallan Walter, 2019; Rosner et al., 2013). Symptoms develop 4 to 7 days after exposure and persist for 5 to 14 days, or several weeks in the case of diarrhea (Laukkanen-Ninios et al., 2012).

$Y$. enterocolitica infections are the fourth most frequently reported bacteriologically related foodborne zoonosis in Europe (EFSA and ECDC, 2019). Reported incidence varies according to country, the method used for diagnostic and the performance of the reporting system. It ranges from less than 1 case per 100,000 in the US (Tack et al., 2019) up to 19.2 in New Zealand (Strydom et al., 2019). Yet the number of illness could be higher when considering underreporting and underdiagnosis (Van Cauteren et al., 2017). As an example, in France, the corrected annual community incidence rate was estimated at 36 cases per 100,000 for yersiniosis, about 30 times higher than the reported incidence rate (Van Cauteren et al., 2017). Microbiological and epidemiological investigations make it possible to identify outbreaks and to trace back the food at the origin of the human cases (Espenhain et al., 2019). Although outbreaks are identified (Konishi et al., 2016; MacDonald et al., 2012), a 
majority of yersiniosis cases caused by $Y$. enterocolitica are not associated with any known outbreak (Marimon et al., 2017) and are classified as sporadic cases. The question of specific environmental or food exposures and their respective weight for these sporadic cases arise.

A large variety of methodological approaches for source attribution of sporadic cases is available (Mughini-Gras et al., 2019). Yet, very few source attribution studies have been carried out for yersinosis. Expert elicitation was the main method applied so far (Batz et al., 2012; Zanabria et al., 2019).

Another way of identifying the sources of sporadic cases is case-control studies. In casecontrol studies, the association of cases with various food exposures is usually measured through odds ratios (ORs) (Pires et al., 2009). Meta-analyses of these studies can provide information on exposure pathways of interest (Devieesschauwer et al., 2019).

The aim of this study is to perform a systematic review of case-control studies for human sporadic $Y$. enterocolitica infections, and, subsequently, to perform a meta-analysis to synthesize data on factors associated with sporadic infection, combining the odds ratio from a selection of relevant studies (Gonzales-Barron et al., 2019). 


\section{Methods}

The systematic review process as well as the meta-analysis model are described in depth in a methodological paper (Gonzales-Barron et al., 2019).

\section{Systematic review}

The keywords were defined attending the review question which is to evaluate the association between a (risk) factor and sporadic $Y$. enterocolitica infections risk in a population exposed to it. This review question was identified to have a typical PECO structure (Population, Exposure, Comparator and Outcome as key elements) (EFSA, 2010)..The literature search was conducted in March 2017 using a combination of keywords related to (1) "Yersinia enterocolitica OR yersiniosis", (2) "case-control OR risk factor OR cohort" (3) "infection OR disease", joined by the logical connector AND. Systematic searches using a combination of suitable keywords were conducted using five bibliographic search engines (ISI Web of Science, PubMed, Scielo, Science Direct and Scopus). The literature search was conducted for English, French, Portuguese and Spanish languages.

The screening criteria followed the PRISMA (Preferred Reporting Items for Systematic Reviews and Meta-analyses) method (Moher et al., 2009). Each reference record was screened by at least two persons for relevance for inclusion in the meta-analysis study, and subsequently, the methodological quality of the "candidate" studies was assessed using preset quality criteria. The first criterion for inclusion was related to the definition of the disease. The included studies should have used a laboratory-based definition of a case, based on a detection or isolation from cultures of the cases. The second criterion refers to the study design. Only the case-control study design was considered.

Moreover, the methodological quality of each "relevant" primary case-control study was assessed using a checklist comprised of six areas of concern. It concerns the appropriate selection of the controls in order to avoid selection bias; the adjustment to correct for confounders, the criteria for the comparability between cases and controls; the data analysis appropriate to the type of design, matched or unmatched; the responses rates for the 
exposed and control groups; and the provision of crude data and/or adjusted ORs and either confidence interval or $p$-value. All these points permitted to assess the overall quality of underlying methods, appropriate statistics, sensible data and quality of reporting/interpretation.

Finally, the quality and completeness of statistical analysis were assessed. Primary studies that passed the screening for relevance were marked as having the potential for bias if they failed to meet at least one of the methodological quality assessment criteria. After careful data extraction, meta-analysis models were adjusted within appropriate risk factor data partitions in order to estimate overall ORs, extracting variability due to primary studies and type of statistical analysis. Diagnostics based on Cook's distance was assessed for every meta-analysis model in order to remove any influential OR originated from studies deemed as having some potential for bias.

\section{Data synthesis}

The joint meta-analytical data was first described using basic descriptive statistics. The number of ORs per country, per year, and per type were calculated. Next, data was partitioned into subsets of categories of risk factors. The used source categorization scheme included travel, host-specific factors and hierarchical pathways of exposure - comprising person-to-person, animal, environment and food routes of transmission. Gonzales-Barron et al. (2019) provides the full list of risk factors, categories and subcategories. Food class and handling are also used for exploring in depth food related factors. The full hierarchy of risk factors is provided in Appendix 1.

Meta-analysis models were then fitted to each of the data partitions or subsets in order to estimate the overall OR due not only for food vehicles but also to travel, host-specific factors and transmission pathways related to person-to-person transmission, animal contact and environmental exposures. In accordance with Gonzales-Barron et al. (2019), the meta- 
analytical models were fitted separately by population type, which are children and mixed population. For some food classes, the effects of handling (i.e., eating raw, undercooked) and setting (i.e., eating out) were assessed by dividing the mean ORs when food was mishandled (or, alternatively, when food was prepared outside the home) by the base ORs.

The statistical analysis was designed to assess the effect of study period and analysis type (univariate/multivariate) on the final result. All meta-analytical models were essentially weighted random-effects linear regression models. A random effect term allow taking into account the study effect ("dependence between studies") nested into the risk factors categories (Gonzales-Barron et al., 2019). Once a meta-analytical model was fitted, influential diagnostics statistics were assessed in order to remove any influential observation originating from studies marked as having potential-for-bias. Publication bias was assessed by funnel plots and statistical tests. Heterogeneity between studies was assessed by three indicators, the between-study variability $\left(\mathrm{T}^{2}\right)$, the QE test investigating residual heterogeneity, the variance of residuals and the intra-class correlation $I^{2}$ (Gonzales-Barron et al., 2019). All analyses were conducted in the $\mathrm{R}$ software implemented with the metafor package (Viechtbauer, 2010).

\section{Results}

\section{Descriptive statistics of the case-control studies}

In the systematic review of risk factors pertaining to sporadic $Y$. enterocolitica infections, a total of 807 bibliographic sources were identified using the defined keywords in the five search engines, from which only 33 passed the full assessment for eligibility comprising case-control/case and cohort studies from both sporadic illnesses and outbreaks (Figure 1). A total of 19 fully-documented case-control studies investigated the source(s) of outbreaks and were thus not included in the study. The meta-analysis was undertaken using 14 primary studies focused on sporadic disease (Figure 1). These published studies were conducted 
between 1987 and 2010. Table 1 compiles a list of the case-control studies along with their main features.

The eligible studies jointly provided 165 categorized odds-ratios for meta-analysis. A total of 66 ORs were retrieved from 8 case-control studies performed before the year 2000, while 99 ORs were excerpted from 6 case-control studies undertaken after 2000. The majority of primary studies investigated sporadic $Y$. enterocolitica infections caused by undetermined serogroups (9 case-control studies) representing $72 \%$ of the ORs. The countries whose case-control studies contributed the largest body of results for sporadic $Y$. enterocolitica infections were Finland (2 studies, 55 ORs), Norway (4 studies, 30 ORs), New Zealand (2 studies, 25 ORs) and Germany (1 study, 23 ORs).

Twelve case-control studies investigated pathways of exposure in adult or mixed population, while only three case-control studies had children as the target population. The only primary study investigating determinants of disease in both children and mixed population was that of Rosner et al. (2012) (Table 1). Whereas $80 \%$ of the ORs originated from exposures evaluated in the mixed/adult population, $20 \%$ of the ORs were quantified from ill children cases. As a rule, because of their distinct routes of exposure, the ORs for children and mixed populations were not joined in a single meta-analysis model, but in separate meta-analyses. Data from both populations were merged only when the ORs belonging to the children population were too few to run a separate meta-analysis model.

\section{Meta-analysis}

For every data partition, the meta-analyzed risk factors are presented in summary tables only when significant (Tables 2, 3 and 4) and when more than one study inform the risk factor. Pooled ORs were considered significant when the lower bound of the $95 \% \mathrm{Cl}$ was equal or greater than 1. Appendix-2 provides values for non-significant factors as well as significant risk factors that arise from a single study. 


\section{Risk factors associated with non food-related transmission pathways}

Among travel, host-related factors, contact with the environment and animals, only a few categories were found as significantly associated with sporadic $Y$. enterocolitica infection cases (Table 2).

Among the main risk categories that were amenable to be meta-analysed, the host-specific factors, associated with chronic diseases in the mixed population, represented as a whole the most important risk factor for acquiring yersiniosis (overall OR=3.132; 95\% Cl: 1.191 8.235). Malnutrition was also associated to yersiniosis in the children population but it arises from a single study (Appendix 2).

Within "contact with animals" categories, the occupational animal contact (overall $O R=1.434$; $95 \% \mathrm{Cl}: 1.164-1.766)$ was the only significant risk factor of sporadic $Y$. enterocolitica infections. It is worthy to mention that, within the mixed population, the significance is mainly explained for occupational exposure data by exposure to pigs (Figure 2). Contacts with pets or occasional contact with farm animals were not associated with sporadic $Y$. enterocolitica infections. A single study explore the contact with wild animals (Rosner et al., 2012) and it does not allow us to draw any conclusions for this risk factor.

For the mixed population and children, sporadic $Y$. enterocolitica infections occurred more frequently among people exposed to untreated drinking water (overall $\mathrm{OR}=1.804 ; 95 \% \mathrm{Cl}$ : $1.230-2.645$ ) (Figure 3). For children, activities in playground were associated with sporadic Y. enterocolitica infections (OR=1.580; 95\% Cl: $1.343-1.857)$. 
In all the meta-analytical data partitions, there was no effect of the study period (before and after 2000) on the measured ORs. The meta-analysis revealed that who travelled recently had no significantly higher $(\mathrm{OR}=2.947 ; 95 \% \mathrm{Cl}: 0.920-9.438)$ probability of getting infected with sporadic $Y$. enterocolitica infections that people who did not travel.

\section{Risk factors associated with food-related transmission pathways}

The studies explore a wide range of foods and food preparation/consumption practices (e.g. hygiene, cooking, and place of consumption). For the mixed population and children, within main large food categories, meat was the only significant risk factor (Table 2). Among meats, pork presents the highest risk factors (Table 3). The risk appears to be higher for children (overall OR=3.416; $95 \% \mathrm{Cl}: 1.893-6.16$ ) than for mixed population (overall OR=1.995; 95\% $\mathrm{Cl}: 1.793-2.219$ ). Two other sub-categories, that is ready-to-eat (RTE) foods (overall OR=1.096; 95\% Cl: $1.010-1.190$ ) and composite dishes - fast food (e.g. sandwiches) (overall OR=1.198; $95 \% \mathrm{Cl}: 1.097-1.308$ ), were also found to be associated with sporadic Y. enterocolitica infections but with considerably lower OR values. The consumption of raw or undercooked pork increased the odds of acquiring $Y$. enterocolitica infections by a factor of 4.215 (Table 4).

For most of the meta-analytical models reported in Table 2, 3 and 4, the statistical tests indicated the absence of potential significant publication bias is above $5 \%$. Exceptions were observed in partitions related to meat and pork in both mixed and children population (Tables 2 and 3), fast food in children (Table 3), and the effect of meat handling (Table 4). For better assessing the publication bias (above 5\%), the funnel plot for those models is given in Figure 4. For all of them, they were an asymmetry, and a lack of non-significant studies with smaller ORs, that could lead to OR overestimation. Moreover, the intra class correlation $\mathrm{I}^{2}$ indicates, in all Tables, a high heterogeneity ( $<75 \%)$. However, residual between-study heterogeneity ( $p$-value often below 0.05 for $Q$ or QE) was observed for the data partitions. 


\section{Discussion}

In this study, the aim was to synthesize data produced by published case-control studies. The weight on common factors associated with sporadic $Y$. enterocolitica infections, among them the relative importance of host-related factors, contact with animals and the environment, as well as food-related factors have been characterized. The results of the case-control surveys confirm the importance of the pig reservoir and of the practices of eating pork meat (raw or undercooked). Indeed pigs are the main carriers of $Y$. enterocolitica (Drummond et al., 2012). Moreover, the main biotype isolated in pork, that is biotype 4 (Raymond et al., 2018) matches with the most common biotype isolated in sporadic cases. Despite this association, it should be noticed that consumption of raw, undercooked pork, is rarely associated with outbreaks (Grahek-Ogden et al., 2007; Self et al., 2017). The situation is the opposite for vegetables and milk products. Both food categories were not identified as risk factors in the meta-analysis (see Appendix 2), although several outbreaks have been associated to these food products, especially for vegetables, in recent years (Espenhain et al., 2019; Konishi et al., 2016; MacDonald et al., 2012).

Untreated drinking water was also identified by the meta-analysis as a risk factor for sporadic $Y$. enterocolitica infections. This finding is also confirmed by epidemiological analysis of some outbreaks that were related to the contamination of food products by untreated drinking water contaminated by Y. enterocolitica (Ackers et al., 2000; Tacket et al., 1985).

Playground attendance was found to be a risk factor for children by the meta-analysis. This finding is somewhat in contradiction with the results from literature where $Y$. enterocolitica strains isolated in the environment are mainly non-pathogenic strains (Le Guern et al., 2016).

It's important to note that all the 14 studies focused on $Y$. enterocolitica. None of them integrated cases of sporadic $Y$. enterocolitica infection associated to other species, especially $Y$. pseudotuberculosis. This latter is thought to have close ecology with $Y$. enterocolitica and is regularly implicated in foodborne outbreaks (Pärn et al., 2015; 
Rimhanen-Finne et al., 2009). Specific case-control studies would help to confirm that risk factors also hold for other enteropathogenic Yersinia species.

A potential difficulty to interpret the results of the meta-analysis is related to the relative importance of biotypes/serotypes in sporadic cases according to the different continents or the different period. Pathogenic $Y$. enterocolitica strains belong to biotypes 1B, 2, 3, 4 and 5, while biotype $1 \mathrm{~A}$ is currently considered non-pathogenic, although its association with diarrheal forms is still debated (Huovinen et al., 2010). Although bioserovar 4/O:3 is the most commonly identified type world-wide in human cases (Hunter et al., 2019; Le Guern et al., 2016; Strydom et al., 2019), some particularities can be identified. For example, biotype 2 has recently emerged as the most common biotype causing yersiniosis in New Zealand (Strydom et al., 2019). In the same way, biotype 1B was the most common biotype in the 1980s for US while now biotype 4 is the most commonly isolated biotype (Savin et al., 2018).

Another limitation of the meta-analysis is related to the origin of the studies. Most of the case-control studies included in the meta-analysis came from Europe, whereas this pathogen is also present in other continents (Duan et al., 2017; Lucero-Estrada et al., 2020). Casecontrol studies from other continents would help to refine our conclusions.

Several sub-typing methods have been developed for outbreak investigation (Strydom et al., 2019), such as biotyping, serotyping, PFGE, MLST and MLVA (Mughini-Gras et al., 2019). These methods have been used in the context of outbreak investigations, but they have never been used as input of source attribution models for sporadic cases of yersiniosis. Frequency-matching models for source attribution could infer the most likely sources of human sporadic cases by comparing their subtype frequencies, weighted by factors like prevalence in these sources and the human exposure to them.

In the same way, the application of WGS methods was until recently limited to outbreak investigations (Espenhain et al., 2019; Inns et al., 2018). The recent publication of the Yersinia cgMLST schema (Savin et al., 2019) will help to apply population structure models 
or machine learning approaches for estimating the attribution of sporadic yersiniosis cases to the potential sources.

\section{Conclusion}

The results of this meta-analysis confirm the importance of pork and untreated drinking water for sporadic $Y$. enterocolitica infections. The study also stresses the role of other routes than food, such as environmental and animal contact. The published case-control studies included this meta-analysis are stored in a database, which will be updated with other relevant studies published in the future.

To refine these results, risk factors should be investigated by $Y$. enterocolitica biotypes. Such investigations, together with specific studies dedicated to $Y$. pseudotuberculosis, could allow to identify species or sub-type source-specific risk factors and to infer the underlying transmission pathways.

\section{Acknowledgments}

The authors would like to thank Anses staff and the members of the Anses Working Group on Source Attribution of Foodborne Diseases: Moez Sanaa, Jean Christophe Augustin, Frédéric Carlin, Julie David, Nathalie Jourdan da-Silva, Lapo Mughini-Gras, Nicole Pavio, Isabelle Villena, and Laurence Watier.

U. Gonzales-Barron and V. Cadavez are grateful to the Foundation for Science and Technology (FCT, Portugal) for financial support through national funds FCT/MCTES to CIMO (UIDB/00690/2020). U. Gonzales-Barron acknowledges FCT, P.I., for the institutional scientific employment programme.

Author Statement

Laurent Guillier: Writing - original draft.

Philippe Fravalo: Writing - Review \& Editing

Alexandre Leclercq: Writing - Review \& Editing 
Anne Thébault: Methodology, Formal analysis, Visualization

Pauline Kooh: Methodology, Project administration

Vasco Cadavez: Methodology, Investigation, Formal analysis.

Ursula Gonzales-Barron: Methodology, Investigation, Formal analysis, Writing-reviewing \& editing.

Declarations of interest: The authors declare no conflict of interest. 


\section{References}

Ackers, M.-L., Schoenfeld, S., Markman, J., Smith, M.G., Nicholson, M.A., DeWitt, W., Cameron, D.N., Griffin, P.M., Slutsker, L., 2000. An outbreak of Yersinia enterocolitica 0:8 infections associated with pasteurized milk. The Journal of Infectious Diseases 181(5), 18341837.

Batz, M.B., Hoffmann, S., Morris Jr, J.G., 2012. Ranking the disease burden of 14 pathogens in food sources in the united states using attribution data from outbreak investigations and expert elicitation. Journal of Food Protection 75(7), 1278-1291.

Boqvist, S., Pettersson, H., Svensson, Å., Andersson, Y., 2009. Sources of sporadic Yersinia enterocolitica infection in children in Sweden, 2004: a case-control study. Epidemiology \& Infection 137(6), 897-905.

Cherchi, G., Pacifico, L., Cossellu, S., Gallisai, D., Zanetti, S., Fadda, G., Chiesa, C., 1995. Prospective study of Yersinia enterocolitica infection in thalassemic patients. The Pediatric Infectious Disease Journal 14(7), 579-584.

Devleesschauwer, B., Pires, S.M., Young, I., Gill, A., Majowicz, S.E., 2019. Associating sporadic, foodborne illness caused by Shiga toxin-producing Escherichia coli with specific foods: a systematic review and meta-analysis of case-control studies. Epidemiology \& Infection 147.

Drummond, N., Murphy, B.P., Ringwood, T., Prentice, M.B., Buckley, J.F., Fanning, S., 2012. Yersinia enterocolitica: a brief review of the issues relating to the zoonotic pathogen, public health challenges, and the pork production chain. Foodborne pathogens and disease 9(3), 179-189.

Duan, R., Liang, J., Zhang, J., Chen, Y., Wang, J., Tong, J., Guo, B., Hu, W., Wang, M., Zhao, J., 2017. Prevalence of Yersinia enterocolitica bioserotype 3/O: 3 among children with diarrhea, China, 2010-2015. Emerging infectious diseases 23(9), 1502.

EFSA, 2010. Application of systematic review methodology to food and feed safety assessments to support decision making. EFSA journal 8(6), $90 \mathrm{p}$. 
EFSA, ECDC, 2019. The European Union One Health 2018 Zoonoses Report. EFSA Journal 17(12), e05926.

El Qouqa, I.A., El Jarou, M.A., Samaha, A.S.A., Al Afifi, A.S., Al Jarousha, A.M.K., 2011. Yersinia enterocolitica infection among children aged less than 12 years: a case-control study. International Journal of Infectious Diseases 15(1), e48-e53.

Espenhain, L., Riess, M., Müller, L., Colombe, S., Ethelberg, S., Litrup, E., Jernberg, C., Kühlmann-Berenzon, S., Lindblad, M., Hove, N.K., 2019. Cross-border outbreak of Yersinia enterocolitica $\mathrm{O} 3$ associated with imported fresh spinach, Sweden and Denmark, March 2019. Eurosurveillance 24(24), 1900368.

Galindo, C.L., Rosenzweig, J.A., Kirtley, M.L., Chopra, A.K., 2011. Pathogenesis of Y. enterocolitica and Y. pseudotuberculosis in human yersiniosis. J Pathog 2011, 182051182051.

Gonzales-Barron, U., Thébault, A., Kooh, P., Watier, L., Sanaa, M., Cadavez, V., 2019. Strategy for systematic review of observational studies and meta-analysis modelling of risk factors for sporadic foodborne diseases. Microbial Risk Analysis.

Grahek-Ogden, D., Schimmer, B., Cudjoe, K.S., Nygård, K., Kapperud, G., 2007. Outbreak of Yersinia enterocolitica serogroup 0:9 infection and processed pork, Norway. Emerging infectious diseases 13(5), 754-756.

Hansen, P.S., Wenzel, B.E., Brix, T.H., Hegedüs, L., 2006. Yersinia enterocolitica infection does not confer an increased risk of thyroid antibodies: evidence from a Danish twin study. Clinical \& Experimental Immunology 146(1), 32-38.

Hoffmann, S., Scallan Walter, E., 2019. Acute Complications and Sequelae from Foodborne Infections: Informing Priorities for Cost of Foodborne Illness Estimates. Foodborne Pathogens and Disease 17(3), 172-177.

Hunter, E., Greig, D.R., Schaefer, U., Wright, M.J., Dallman, T.J., McNally, A., Jenkins, C., 2019. Identification and typing of Yersinia enterocolitica and Yersinia pseudotuberculosis isolated from human clinical specimens in England between 2004 and 2018. Journal of Medical Microbiology 68(4), 538-548. 
Huovinen, E., Sihvonen, L.M., Virtanen, M.J., Haukka, K., Siitonen, A., Kuusi, M., 2010. Symptoms and sources of Yersinia enterocolitica-infection: a case-control study. BMC infectious diseases 10(1), 122.

Inns, T., Flanagan, S., Greig, D.R., Jenkins, C., Seddon, K., Chin, T., Cartwright, J., 2018. First use of whole-genome sequencing to investigate a cluster of Yersinia enterocolitica, Liverpool, United Kingdom, 2017. Journal of medical microbiology 67(12), 1747-1752.

Konishi, N., Ishitsuka, R., Yokoyama, K., Saiki, D., Akase, S., Monma, C., Hirai, A., Sadamasu, K., Kai, A., 2016. Two outbreaks of Yersinia enterocolitica O: 8 infections in Tokyo and the characterization of isolates. Kansenshogaku zasshi. The Journal of the Japanese Association for Infectious Diseases 90(1), 66-72.

Laukkanen-Ninios, R., Fredriksson-Ahomaa, M., Fraque, S., 2012. Epidemiology, virulence genes, and reservoirs of enteropathogenic Yersinia species, Foodborne and waterborne bacterial pathogens: epidemiology, evolution and molecular biology. Caister Academic Press, Norfolk, pp. 269-287.

Le Guern, A.-S., Martin, L., Savin, C., Carniel, E., 2016. Yersiniosis in France: overview and potential sources of infection. International Journal of Infectious Diseases 46, 1-7.

Lucero-Estrada, C., Favier, G.I., Escudero, M.E., 2020. An overview of Yersinia enterocolitica and related species in samples of different origin from San Luis, Argentina. Food Microbiology 86, 103345.

MacDonald, E., Heier, B.T., Nygård, K., Stalheim, T., Cudjoe, K.S., Skjerdal, T., Wester, A.L., Lindstedt, B.-A., Stavnes, T.-L., Vold, L., 2012. Yersinia enterocolitica outbreak associated with ready-to-eat salad mix, Norway, 2011. Emerging infectious diseases 18(9), 1496.

Marimon, J., Figueroa, R., Idigoras, P., Gomariz, M., Alkorta, M., Cilla, G., Pérez-Trallero, E., 2017. Thirty years of human infections caused by Yersinia enterocolitica in northern Spain: 1985-2014. Epidemiology \& Infection 145(11), 2197-2203.

Moher, D., Liberati, A., Tetzlaff, J., Altman, D.G., Group, P., 2009. Preferred reporting items for systematic reviews and meta-analyses: the PRISMA statement. PLoS med 6(7), e1000097. 
Mughini-Gras, L., Kooh, P., Fravalo, P., Augustin, J.-C., Guillier, L., David, J., Thébault, A., Carlin, F., Leclercq, A., Jourdan Da-Silva, N., Pavio, N., Villena, I., Sanaa, M., Watier, L., 2019. Critical orientation in the jungle of currently available methods and types of data for source attribution of foodborne diseases. Front Microbiol 10, 2578-2578.

Ostroff, S., Kapperud, G., Hutwagner, L., Nesbakken, T., Bean, N., Lassen, J., Tauxe, R., 1994. Sources of sporadic Yersinia enterocolitica infections in Norway: a prospective casecontrol study. Epidemiology \& Infection 112(1), 133-141.

Ostroff, S.M., Kapperud, G., Lassen, J., Aasen, S., Tauxe, R.V., 1992. Clinical features of sporadic Yersinia enterocolitica infections in Norway. Journal of infectious diseases 166(4), 812-817.

Pärn, T., Hallanvuo, S., Salmenlinna, S., Pihlajasaari, A., Heikkinen, S., Telkki-Nykänen, H., Hakkinen, M., Ollgren, J., Huusko, S., Rimhanen-Finne, R., 2015. Outbreak of Yersinia pseudotuberculosis 0:1 infection associated with raw milk consumption, Finland, spring 2014. Eurosurveillance 20(40), 30033.

Raymond, P., Houard, E., Denis, M., Esnault, E., 2018. Diversity of Yersinia enterocolitica isolated from pigs in a French slaughterhouse over 2 years. MicrobiologyOpen, e751.

Rimhanen-Finne, R., Niskanen, T., Hallanvuo, S., Makary, P., Haukka, K., Pajunen, S., Siitonen, A., Ristolainen, R., Pöyry, H., Ollgren, J., 2009. Yersinia pseudotuberculosis causing a large outbreak associated with carrots in Finland, 2006. Epidemiology \& Infection $137(3), 342-347$.

Rosner, B., Stark, K., Höhle, M., Werber, D., 2012. Risk factors for sporadic Yersinia enterocolitica infections, Germany 2009-2010. Epidemiology \& Infection 140(10), 17381747.

Rosner, B.M., Werber, D., Höhle, M., Stark, K., 2013. Clinical aspects and self-reported symptoms of sequelae of Yersinia enterocolitica infections in a population-based study, Germany 2009-2010. BMC infectious diseases 13(1), 236. 
Sæbø, A., Kapperud, G., Lassen, J., Waage, J., 1994. Prevalence of antibodies to Yersinia enterocolitica 0:3 among Norwegian military recruits: Association with risk factors and clinical manifestations. European journal of epidemiology 10(6), 749-755.

Satterthwaite, P., Pritchard, K., Floyd, D., Law, B., 1999. A case-control study of Yersinia enterocolitica infections in Auckland. Australian and New Zealand Journal of Public Health 23(5), 482-485.

Savin, C., Criscuolo, A., Guglielmini, J., Le Guern, A.-S., Carniel, E., Pizarro-Cerdá, J., Brisse, S., 2019. Genus-wide Yersinia core-genome multilocus sequence typing for species identification and strain characterization. Microb Genom 5(10), e000301.

Savin, C., Le Guern, A.-S., Lefranc, M., Brémont, S., Carniel, E., Pizarro-Cerdá, J., 2018. Isolation of a Yersinia enterocolitica biotype 1B strain in France, and evaluation of its genetic relatedness to other European and North American biotype 1B strains. Emerg Microbes Infect 7(1), 121-121.

Self, J., Luna-Gierke, R., Fothergill, A., Holt, K., Vieira, A., 2017. Outbreaks attributed to pork in the United States, 1998-2015. Epidemiology \& Infection 145(14), 2980-2990.

Seuri, M., Granfors, K., 1992. Possible confounders of the relationship between occupational swine contact and Yersinia enterocolitica $0: 3$ and $0: 9$ antibodies. European journal of epidemiology 8(4), 532-538.

Skjerve, E., Kapperud, G., 1991. Epidemiology of human Yersinia enterocolitica, Campylobacter jejunilcoli and Salmonella Typhimurium 0:4,12 infections in Norway, 6th International Symposium on Veterinary Epidemiology and Economics. Ottawa, Canada, pp. 568-570.

Strydom, H., Wang, J., Paine, S., Dyet, K., Cullen, K., Wright, J., 2019. Evaluating sub-typing methods for pathogenic Yersinia enterocolitica to support outbreak investigations in New Zealand. Epidemiology and Infection 147, e186.

Tack, D.M., Marder, E.P., Griffin, P.M., Cieslak, P.R., Dunn, J., Hurd, S., Scallan, E., Lathrop, S., Muse, A., Ryan, P., Smith, K., Tobin-D'Angelo, M., Vugia, D.J., Holt, K.G., Wolpert, B.J., Tauxe, R., Geissler, A.L., 2019. Preliminary incidence and trends of infections with 
pathogens transmitted commonly through food - Foodborne diseases active surveillance network, 10 U.S. Sites, 2015-2018. MMWR Morb Mortal Wkly Rep 68(16), 369-373.

Tacket, C., Ballard, J., Harris, N., Allard, J., Nolan, C., Quan, T., Cohen, M., 1985. An outbreak of Yersinia enterocolitica infections caused by contaminated tofu (soybean curd). American journal of epidemiology 121(5), 705-711.

Tauxe, R., Wauters, G., Goossens, V., Van Noyen, R., Vandepitte, J., Martin, S., De Mol, P., Thiers, G., 1987. Yersinia enterocolitica infections and pork: the missing link. The Lancet 329(8542), 1129-1132.

Van Cauteren, D., Le Strat, Y., Sommen, C., Bruyand, M., Tourdjman, M., Jourdan Da Silva, N., Couturier, E., Fournet, N., de Valk, H., Desenclos, J.-C., 2017. Estimated Annual Numbers of Foodborne Pathogen-Associated Illnesses, Hospitalizations, and Deaths, France, 2008-2013. Emerging infectious diseases 23(9), 1486-1492.

Wauters, G., 1987. Revised biogrouping scheme of Yersinia enterocolitica. Contrib Microbiol Immunol 9, 14-21.

Wilson, N., Baker, M., Edwards, R., Simmons, G., 2008. Case-case analysis of enteric diseases with routine surveillance data: Potential use and example results. Epidemiologic Perspectives \& Innovations 5(1), 6.

Zanabria, R., Racicot, M., Leroux, A., Xucen, L., Cormier, M., Ferrouillet, C., Arsenault, J., Mackay, A., Griffiths, M., Holley, R., Gill, T., Charlebois, S., Farber, J., Fazil, A., Quessy, S., 2019. Source attribution at the food sub-product level for the development of the Canadian Food Inspection Agency risk assessment model. Int. J. Food Microbiol. 305, 108241. 
Figure captions

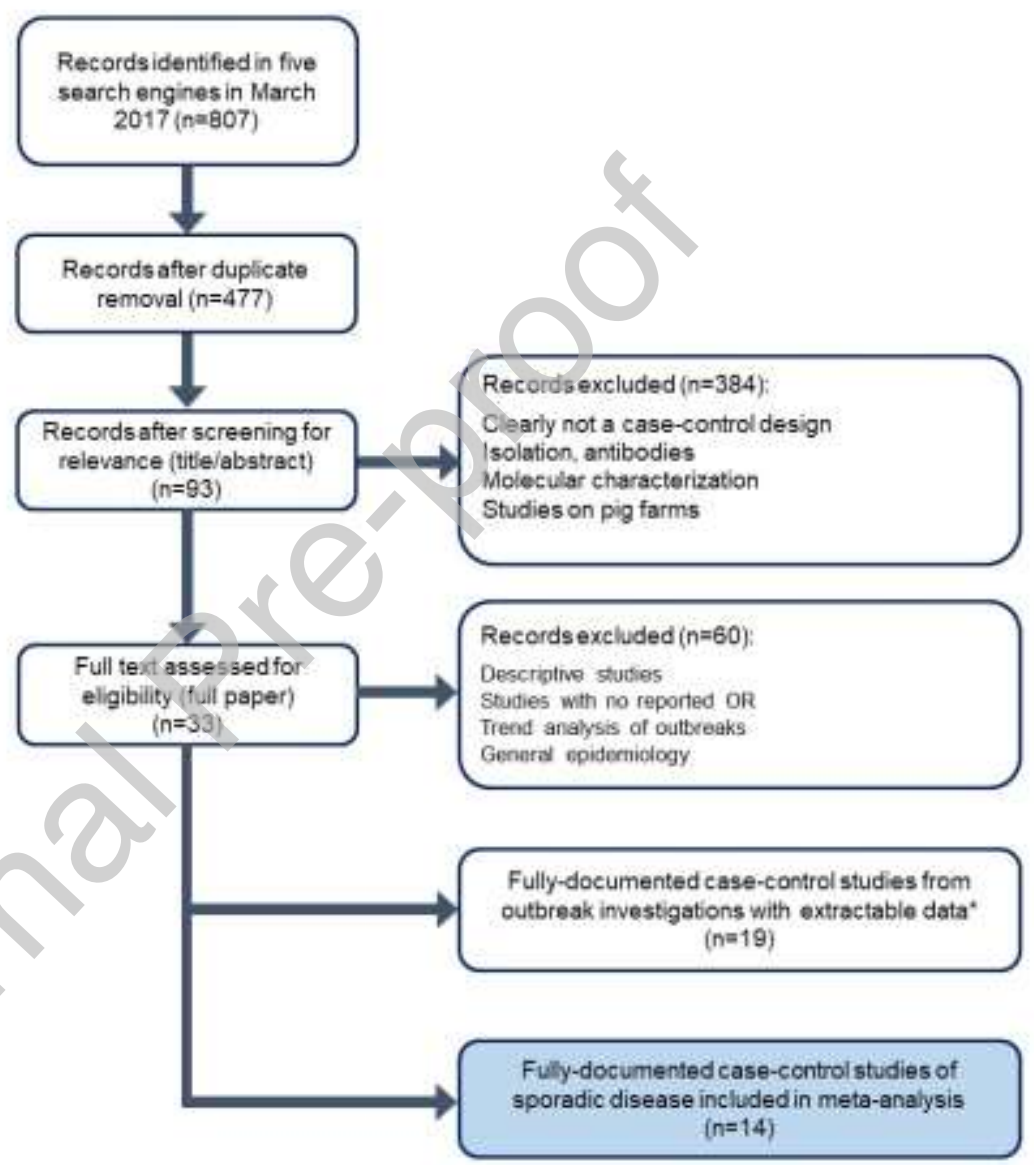


Figure 1. Flow chart of the literature search for case-control studies of sporadic $Y$. enterocolitica infections. $\left(^{\star}\right)$ Kept in JabRef file and available upon request.

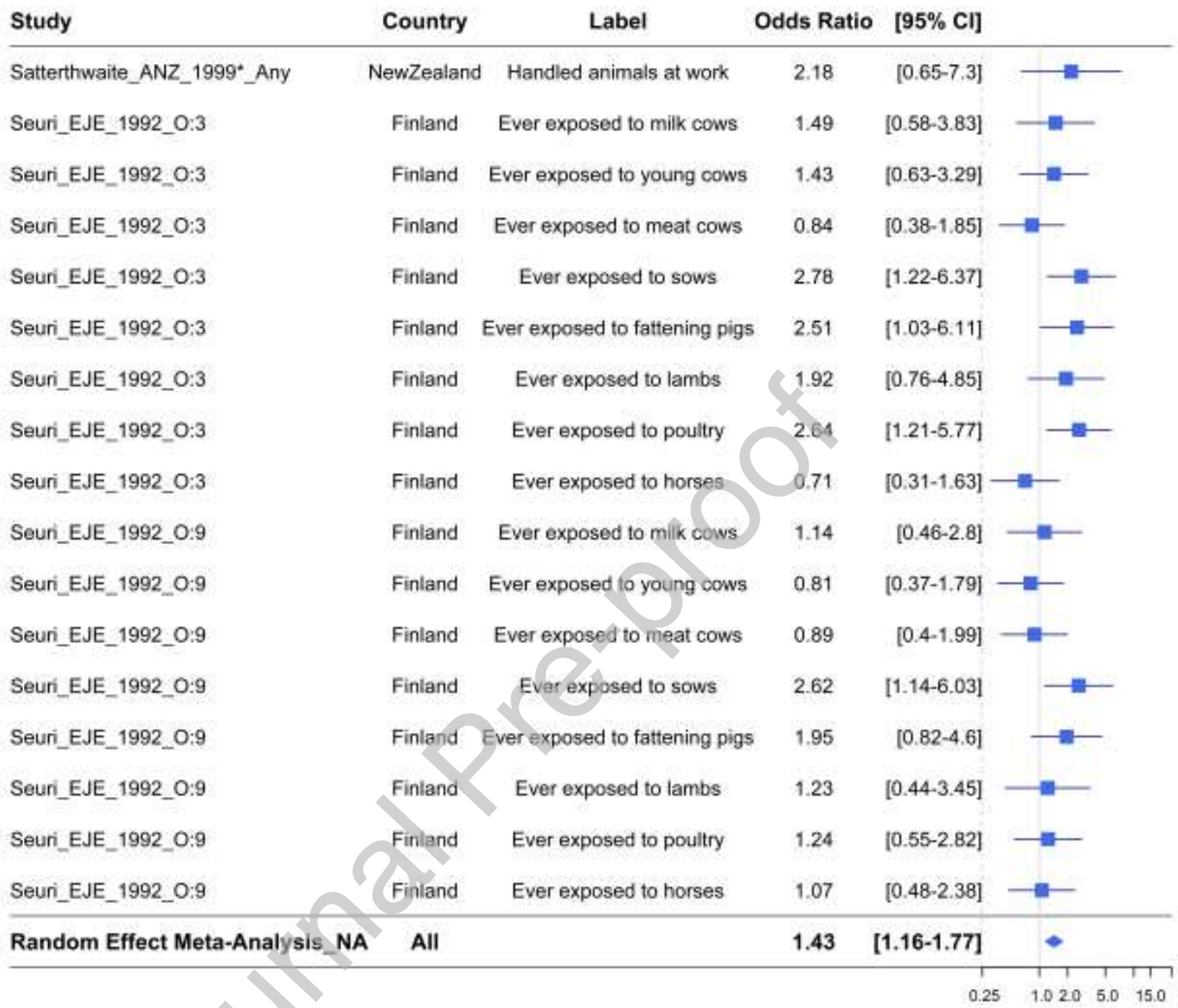


Figure 2. Forest plot of the associations of yersiniosis with the category of “occupational animal contact" in the mixed population (*adjusted OR, N=17 ORs).

\begin{tabular}{|c|c|c|c|c|c|c|}
\hline Study & Country & Label & Odds Ratio & o $[95 \% \mathrm{CI}]$ & & \\
\hline Ostroff_Epilnf_1994 & Norway & Untreated water & 2.76 & {$[1,19-6.43]$} & & $\longrightarrow$ \\
\hline Qouqa_IJID_2011 & Palestine & Non-chlorinated water supply & 2.93 & {$[1,02-8.44]$} & & $\longrightarrow$ \\
\hline Qouqa_IJID_2011 & Palestine & Non-chlorinated water supply & 2.83 & [0.99-8.07] & & $\longrightarrow$ \\
\hline Qouqa_IJID_2011* & Palestine & Non-chlorinated water supply & 3.05 & [0.81-11.43] & & $\Rightarrow$ \\
\hline Saebo_EJE_1994 & Norway & Drinks municipal water & 0.74 & [0.36-1.55] & $\rightarrow$ & - \\
\hline Saebo_EJE_1994 & Norway & Drinks private well water & 1.35 & [0.65-2.75] & & $-\pi-$ \\
\hline Saebo_EJE_1994 & Norway & Undisinfected water & 0.73 & {$[0,34-1.55]$} & $\rightarrow-$ & - \\
\hline Saebo_EJE_1994* & Norway & Drinks private wall water & 3.4 & {$[1.49-7.73]$} & & $\rightarrow-$ \\
\hline Skjerve_ProcVetEpi_1991 & Norway & Undisinfected water & 2.8 & {$[1.2-6.4]$} & & $\rightarrow-$ \\
\hline Wilson_EPI_2008 & NewZealand & Untreated water & 1.28 & [0.92-1.78] & & $=$ \\
\hline Random Effect Meta-Analysis & All & & 1.8 & [1.23-2.65] & & - \\
\hline
\end{tabular}

Figure 3. Forest plot of the associations of sporadic $Y$. enterocolitica infections with exposure to the category of untreated drinking water. (Legend * adjusted $\mathrm{OR}, \mathrm{N}=10$ ). 

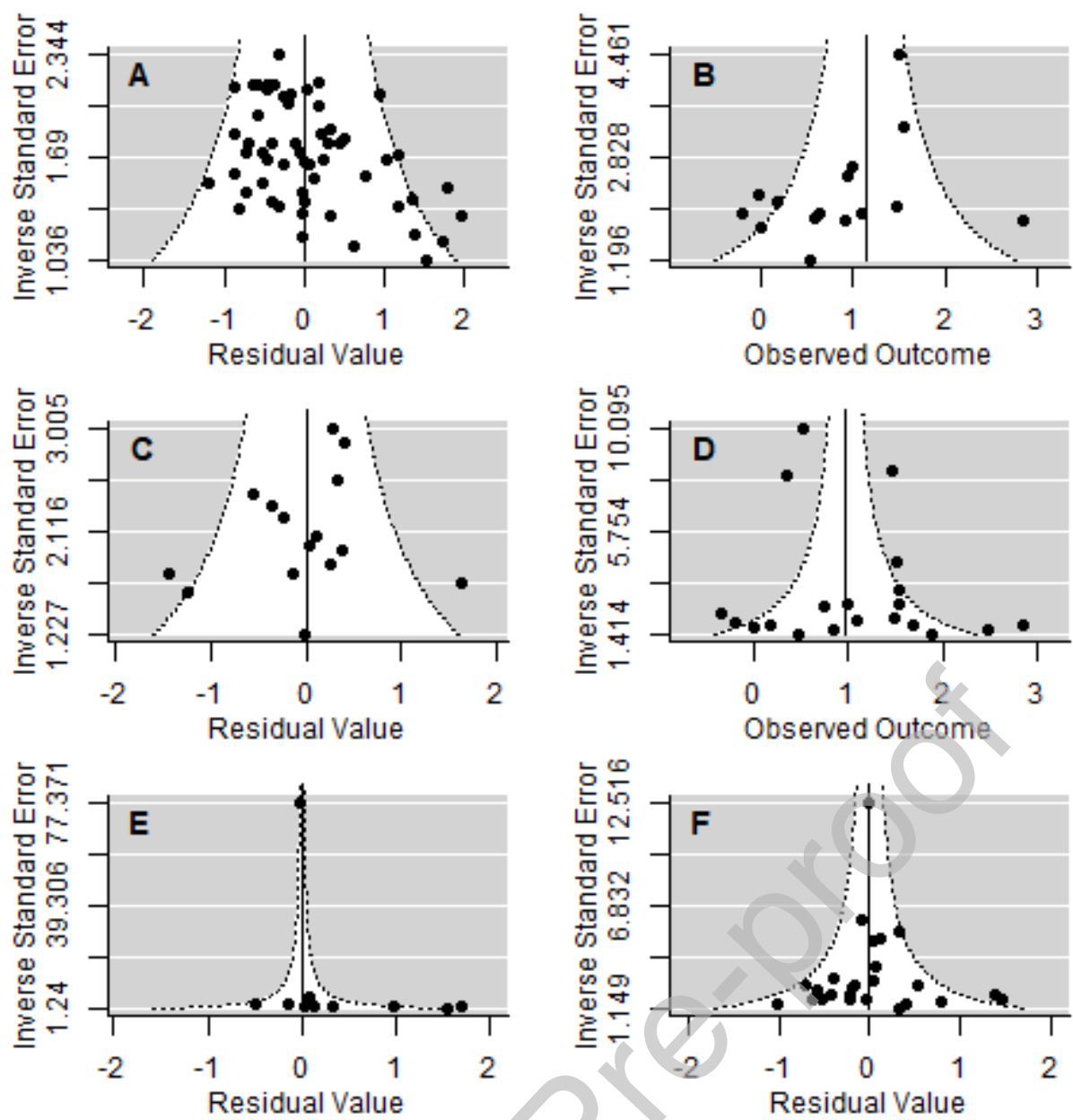

Figure 4: Funnel plots of studies investigating categorized risk factors. A) Food in mixed, B) Food in children, C) Meat in children D) Meat in mixed E) Composite (Fast food) and F) Handling (cooking). 
Appendix 1: List of risk factors used for meta-analysis of food-borne pathogen

Table A1-1. Categorization scheme of main risk factors defined for transmission of foodborne diseases (from Gonzales-Barron et al., 2019)

\begin{tabular}{ll}
\hline Risk factors & Sub-categories \\
\hline Environnement & Day care attendance \\
& Farm environment \\
& Forestry \\
& Playground \\
& Recreational water \\
& Untreated drinking water \\
& Waste water \\
\hline Animals & Pets \\
Farm animals \\
Flies/rodents \\
Occupational exposure \\
Wild animals \\
\hline Antiacids \\
Blood Transfusion \\
Breastfeeding \\
Chronic diseases \\
Malnutrition \\
Immunocompromising conditions \\
Other medical conditions \\
\hline Contact in household \\
\hline Dost-specific
\end{tabular}


Occupational exposure

Venerian transmission

\begin{tabular}{ll}
\hline Poor handwashing/handling & \\
\hline Poor personal hygiene & \\
\hline Travel & Abroad \\
& Any \\
& Inside \\
\hline Food & See Table A2 \\
\hline
\end{tabular}


Table A2. Categorization scheme of food risk factors defined for transmission of foodborne diseases (from Gonzales-Barron et al., 2019)

\begin{tabular}{|c|c|}
\hline Category & Subcategory \\
\hline Beverages & Water \\
\hline \multirow{3}{*}{ Composite } & Dishes \\
\hline & Fast food \\
\hline & RTE composite \\
\hline \multirow{9}{*}{ Dairy } & Cheese \\
\hline & Fats \\
\hline & Milk \\
\hline & Milk formula \\
\hline & Powder \\
\hline & Raw milk \\
\hline & Undefined \\
\hline & Raw dairy \\
\hline & RTE Dairy \\
\hline \multirow{4}{*}{ Eggs } & Egg products \\
\hline & Eggs \\
\hline & Raw eggs \\
\hline & Undercooked eggs \\
\hline \multirow{4}{*}{ Meat } & Beef \\
\hline & Undercooked beef \\
\hline & \\
\hline & Other red meats \\
\hline
\end{tabular}

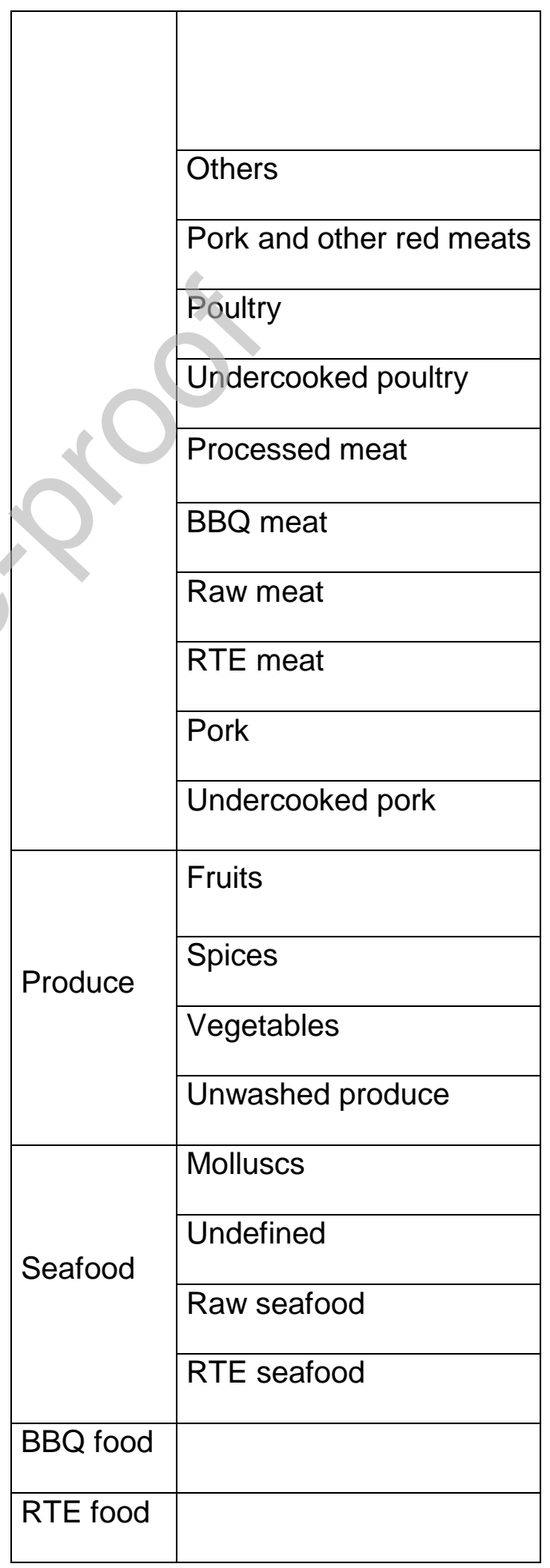




\section{Appendix 2: Non-significant results or isolated study}

\section{- Main risk factors}

\begin{tabular}{|c|c|c|c|}
\hline Population & Risk factor & $\begin{array}{c}\text { Pooled OR } \\
{[95 \% \mathrm{C} \mid]}\end{array}$ & $N / n^{*}$ \\
\hline \multicolumn{4}{|c|}{ Travel } \\
\hline Mixed & Travel Abroad & $2.947[0.920-9.434]$ & $3 / 5$ \\
\hline \multirow[t]{2}{*}{ Children } & Malnutrition & $4.782[2.730-8.378]$ & $1 / 4$ \\
\hline & \multicolumn{3}{|c|}{ Animals } \\
\hline \multirow{3}{*}{ Mixed and children } & Pets & $1.219[0.809-1.838]$ & $4 / 6$ \\
\hline & Wild animals & $1.734[1.305-2.304]$ & $1 / 3$ \\
\hline & Farm animals & 0.834 [ $0.200-3.472]$ & $1 / 6$ \\
\hline \multicolumn{4}{|c|}{ Environment } \\
\hline \multirow{2}{*}{ lixed } & Farm environment & $1.158[0.552-2.427]$ & $2 / 3$ \\
\hline & Wastewater & $2.458[1.155-5.233]$ & $1 / 2$ \\
\hline \multicolumn{4}{|c|}{ Food } \\
\hline \multirow{2}{*}{ Mixed } & Composite & $1.326[0.766-2.296]$ & $3 / 9$ \\
\hline & Produce & $1.202[0.659-2.193]$ & $1 / 11$ \\
\hline
\end{tabular}

${ }^{*} \mathrm{~N} /$ n Number of studies/number of OR

\section{- Disaggregated risk factors}




\begin{tabular}{|c|c|c|c|c|}
\hline Risk Factor & $\begin{array}{c}\text { Risk factor } \\
\text { precise }\end{array}$ & Population & $\begin{array}{l}\text { Pooled OR } \\
{[95 \% \mathrm{Cl}]}\end{array}$ & $N / n^{*}$ \\
\hline \multirow{5}{*}{ Meat } & Beef & \multirow{5}{*}{ Mixed } & $0.734[0.636-0.847]$ & $2 / 5$ \\
\hline & $\begin{array}{l}\text { Other red } \\
\text { meats }\end{array}$ & & $\begin{array}{c}0.9793[0.896- \\
1.070]\end{array}$ & $2 / 7$ \\
\hline & Others & & $1.310[0.893-1.920]$ & $1 / 5$ \\
\hline & Poultry & & $1.564[0.787-3.106]$ & $1 / 2$ \\
\hline & $\begin{array}{c}\text { Processed } \\
\text { meat }\end{array}$ & & $1.033[0.970-1.101]$ & $4 / 7$ \\
\hline Meat & $\begin{array}{c}\text { Processed } \\
\text { meat }\end{array}$ & Children & $2.449[1.232-4.867]$ & $1 / 7$ \\
\hline Composite & Dishes & Mixed & $1.306[0.793-2.149]$ & $3 / 6$ \\
\hline
\end{tabular}

*N/n Number of studies/number of OR 


\section{Tables}

Table 1. Characteristics of case-control/cohort studies investigating sources of sporadic

\section{Y. enterocolitica infections included in the meta-analysis.}

\begin{tabular}{|c|c|c|c|c|c|c|c|}
\hline Study ID & Country & $\begin{array}{l}\text { Study } \\
\text { period }\end{array}$ & Population & $\begin{array}{l}\text { Study \& } \\
\text { Design }\end{array}$ & $\begin{array}{c}\text { Analysis \& } \\
\text { Model }^{*} \\
\text { (number of } \\
\text { ORs) }\end{array}$ & \# cases/controls & Quality \\
\hline \multirow{2}{*}{$\begin{array}{l}\text { Boqvist et al. } \\
2009\end{array}$} & \multirow[t]{2}{*}{ Sweden } & \multirow[t]{2}{*}{2004} & Children & \multirow[t]{2}{*}{ Matched } & Uni-UL (12) & 117 cases & \multirow[t]{2}{*}{ Good } \\
\hline & & & $<6$ y/o & & Multi-UL (5) & 339 controls & \\
\hline \multirow{2}{*}{$\begin{array}{c}\text { Cherchi et al. } \\
1995\end{array}$} & \multirow[t]{2}{*}{ Italy } & \multirow{2}{*}{$\begin{array}{l}1993- \\
1994\end{array}$} & \multirow[t]{2}{*}{ Mixed } & \multirow{2}{*}{$\begin{array}{l}\text { Prospective } \\
\text { cohort, UM }\end{array}$} & Uni-Chi (1) & 16 cases & \multirow[t]{2}{*}{ Good } \\
\hline & & & & & & 228 controls & \\
\hline \multirow{2}{*}{$\begin{array}{l}\text { Hansen et al. } \\
2006\end{array}$} & \multirow[t]{2}{*}{ Denmark } & \multirow[t]{2}{*}{2006} & \multirow[t]{2}{*}{ Mixed } & \multirow[t]{2}{*}{ Unmatched } & Uni-Chi (2) & 129 cases & \multirow[t]{2}{*}{ Good } \\
\hline & & & & & & 165 controls & \\
\hline \multirow[t]{4}{*}{$\begin{array}{l}\text { Huovinen et al. } \\
2010\end{array}$} & \multirow[t]{4}{*}{ Finland } & \multirow[t]{4}{*}{2006} & \multirow[t]{4}{*}{ Mixed } & \multirow[t]{4}{*}{ Matched } & \multirow[t]{4}{*}{ Uni-CL (38) } & $\begin{array}{c}54 \text { 3-4/O:3 or } \\
2 / 0: 9\end{array}$ & \multirow[t]{4}{*}{ Good } \\
\hline & & & & & & 133 controls & \\
\hline & & & & & & 98 Biotype $1 \mathrm{~A}$ & \\
\hline & & & & & & 251 controls & \\
\hline \multirow{2}{*}{$\begin{array}{c}\text { Ostroff et al. } \\
1992\end{array}$} & \multirow[t]{2}{*}{ Norway } & \multirow{2}{*}{$\begin{array}{l}1988- \\
1990\end{array}$} & Mixed & \multirow[t]{2}{*}{ Matched } & Uni-MH (1) & $660: 3$ & Good \\
\hline & & & & & & 131 controls & \\
\hline Ostroff et al. & Norway & 1988- & Mixed & Matched & Uni-CL (11) & $670: 3$ & Good \\
\hline 1994 & & 1990 & & & & 132 controls & \\
\hline El Qouqa et al. & Palestine & 2010 & Children & Matched & Uni-Chi (8) & 16 cases & Good \\
\hline 2011 & & & $<12$ y/o & & Multi-UL (3) & 128 controls & \\
\hline & & & & & & 16 cases & Poor \\
\hline & & & & & & $144 \mathrm{Gl}$ controls & \\
\hline Rosner et al. & Germany & 2009- & Children & Unmatched & Uni-UL (12) & 571 cases & Good \\
\hline 2012 & & 2010 & Mixed & & Multi-UL (11) & 1798 controls & \\
\hline Saebo et al. & Norway & 1988- & Adult & Unmatched & Uni-Chi (15) & 56 seropositive & Good \\
\hline 1994 & & 1990 & & & Multi-UL (1) & $(\lg G+)(O: 3)$ & \\
\hline & & & & & & $\begin{array}{c}699 \text { seronegative } \\
\text { IgG- }\end{array}$ & \\
\hline Satterthwaite et & New & 1988- & Mixed & Unmatched & Uni-UL (18) & 186 cases & Poor \\
\hline al. 1999 & Zealand & 1993 & & & & 360 controls & \\
\hline Seuri \& & Finland & 1991 & Mixed & Cohort & Uni-Chi (16) & 29 O:3/O:9 & Good \\
\hline Granfors 1992 & & & & Unmatched & & 233 controls & \\
\hline Skjerve \& & Norway & 1991 & Mixed & Matched & Uni-MH (2) & 63 cases & Good \\
\hline Kapperud 1991 & & & & & & 123 controls & \\
\hline Tauxe et al., & Belgium & 1987 & Mixed & Unmatched & Uni-Chi (1) & 40 cases & Good \\
\hline 1987 & & & & & & ? controls ${ }^{\star \star}$ & \\
\hline Wilson et al. & New & 2006 & Mixed & Unmatched & Uni-Chi (7) & 285 Yersinia & Poor \\
\hline 2008 & Zealand & & & & & $\begin{array}{c}5038 \\
\text { Campylobacter }\end{array}$ & \\
\hline
\end{tabular}

${ }^{*}$ ) Analysis can be univariate (Uni) and multivariate (Multi) while model can be chi-square (Chi), MantelHaenzel $(\mathrm{MH})$, unconditional logistic $(\mathrm{UL})$ and conditional logistic $(\mathrm{CL})$ 
$\left(^{* *}\right)$ Number of controls not stated in the study 
Table 2. Results of the meta-analysis on the main risk factors of sporadic $Y$. enterocolitica infections

\begin{tabular}{|c|c|c|c|c|c|c|c|}
\hline Population & Risk factor & $\begin{array}{c}\text { Pooled } \\
\text { OR } \\
\text { [IC95\%] }\end{array}$ & $N / n^{*}$ & $\mathrm{p}$-value of risk factor & $\begin{array}{c}\text { Publication } \\
\text { bias } \\
\text { p-value }\end{array}$ & $\begin{array}{c}\text { Points } \\
\text { removed } \\
\star *\end{array}$ & $\begin{array}{l}\text { Heterogeneity } \\
\text { analysis }\end{array}$ \\
\hline \multicolumn{8}{|c|}{ Host specific } \\
\hline Mixed & Host specific & $\begin{array}{c}3.132 \\
{[1.191-} \\
8.235]\end{array}$ & $4 / 5$ & 0.021 & 0.956 & 0 & $\begin{array}{l}\text { Tau2 }=0.777 \\
Q(d f=4)=35.551, \\
p-v a l<.0001 \\
S 2=1.241 \\
l 2=38,491\end{array}$ \\
\hline \multicolumn{8}{|c|}{ Animal } \\
\hline Mixed & Occupational exposure & $\begin{array}{c}1.434 \\
{[1.164-} \\
1.766]\end{array}$ & $2 / 17$ & 0.001 & 0.155 & 1 & $\begin{array}{l}\text { Tau2 }=0,090 \\
\mathrm{QE}(\mathrm{df}=28)= \\
32.017, \mathrm{p}-\mathrm{val}= \\
0.274 \\
\mathrm{~S} 2=0.220 \\
\mathrm{I} 2=28.915\end{array}$ \\
\hline \multicolumn{8}{|c|}{ Environment } \\
\hline Mixed and Children & Untreated drinking water & $\begin{array}{c}1.804 \\
{[1.230-} \\
2.645]\end{array}$ & $5 / 10$ & 0.003 & 0221 & 1 & $\begin{array}{l}\text { Tau2 }=0.295 \\
\mathrm{QE}(\mathrm{df}=16)= \\
25.349, \mathrm{p}-\mathrm{val}=\end{array}$ \\
\hline Children & Playground & $\begin{array}{c}1.580 \\
{[1.343-} \\
1.857] \\
\end{array}$ & $2 / 5$ & $<.0001$ & $0 . \angle 2<1$ & 1 & $\begin{array}{l}0.064 \\
S 2=0.232 \\
\mathrm{I} 2=55.919\end{array}$ \\
\hline \multicolumn{8}{|c|}{ Food } \\
\hline Mixed & Meat & $\begin{array}{c}1.870 \\
{[1.093-} \\
3.200]\end{array}$ & $6 / 42$ & 0.0224 & 0.008 & 2 & $\begin{array}{l}\text { Tau2 }=0.372 \\
\mathrm{QE}(\mathrm{df}=59)= \\
368.714, \mathrm{p}-\mathrm{val}< \\
.0001 \\
\mathrm{~S} 2=0.538 \\
\mathrm{I} 2=40.903\end{array}$ \\
\hline Children & Meat & $\begin{array}{c}3.119 \\
{[1.550-} \\
6.274]\end{array}$ & $2 / 15$ & 0.001 & 0.013 & 0 & $\begin{array}{l}\text { Tau2 }=0.230 \\
Q(d f=14)= \\
38.705, p-v a l= \\
0.0004 \\
\text { S2 }=0.620 \\
\mid 2=27.056\end{array}$ \\
\hline
\end{tabular}

${ }^{*} \mathrm{~N} / \mathrm{n}$ Number of studies/number of OR;** points removed by sensitivity analysis, all results are given after removing data concerned; ***Between-study variability (тau2), test for residual heterogeneity (QE), variance of residuals $\left(\mathrm{s}^{2}\right)$, intra-class correlation $\left(\mathrm{I}^{2}\right)$ 
Table 3: Results of the meta-analysis on disaggregated food risk factors of sporadic $Y$. enterocolitica infections

\begin{tabular}{|c|c|c|c|c|c|c|c|c|}
\hline Food category & $\begin{array}{l}\text { Food } \\
\text { sub- } \\
\text { category }\end{array}$ & Population & $\begin{array}{l}\text { Pooled } \\
\text { OR } \\
\text { [IC95\%] }\end{array}$ & $N / n^{*}$ & p-value of risk factor & $\begin{array}{l}\text { Publication bias } \\
\text { p-value }\end{array}$ & $\begin{array}{l}\text { Points } \\
\text { removed }\end{array}$ & Heterogeneity analysis ${ }^{\star * *}$ \\
\hline Meat & Pork & Mixed & $\begin{array}{c}1.995 \\
{[1.793-} \\
2.219]\end{array}$ & $4 / 13$ & $<.0001$ & 0.093 & 3 & $\begin{array}{l}\text { Tau2 }=0.000 \\
Q E(d f=33)=142.376, p-\text { val }<.0001 \\
S 2=0.403 \\
I 2=0.000\end{array}$ \\
\hline Meat & Pork & Children & $\begin{array}{c}3.416 \\
{[1.893-} \\
6.165]\end{array}$ & $2 / 8$ & $<.0001$ & 0.020 & 0 & $\begin{array}{l}\text { Tau2 }=0.145 \\
Q E(d f=13)=27.899, p-v a l=0.009 \\
S 2=0.539 \\
I 2=21.127\end{array}$ \\
\hline Meat & Pork & Mixed + Children & $\begin{array}{c}2.638 \\
{[1.584-} \\
4.395]\end{array}$ & $5 / 21$ & 0.0002 & $1.053 \mathrm{e}-07$ & 1 & $\begin{array}{l}\text { Tau2 }=0.225 \\
Q(d f=20)=129.349, p-v a l<.0001 \\
S 2=0.731 \\
I 2=23.543\end{array}$ \\
\hline Composite & Fast food & Mixed & $\begin{array}{c}1.198 \\
{[1.097-} \\
1.308]\end{array}$ & $3 / 4$ & $<.0001$ & & 0 & $\begin{array}{l}\text { Tau2 }=0.152 \\
\mathrm{QE}(\mathrm{df}=8)=40.115, \mathrm{p}-\mathrm{val}<.0001 \\
\mathrm{~S} 2=0.546 \\
\mathrm{I} 2=21.756\end{array}$ \\
\hline RTE food & & Mixed + Children & $\begin{array}{c}1.096 \\
{[1.010-} \\
1.190]\end{array}$ & $4 / 7$ & 0.028 & 0.139 & 1 & $\begin{array}{l}\text { Tau2 }=0.000 \\
Q(d f=6)=8.147, p-v a l=0.228 \\
S 2=0.202 \\
I 2=0.000\end{array}$ \\
\hline
\end{tabular}

${ }^{*} \mathrm{~N} / \mathrm{n}$ Number of studies/number of OR;** points removed by sensitivity analysis, all results are given after removing data concerned; ${ }^{* * *}$ Between-study variability (тau2), test for residual heterogeneity (QE), variance of residuals $\left(\mathrm{s}^{2}\right)$, intra-class correlation $\left(\mathrm{I}^{2}\right)$. 
Table 4. Effect of food handling on pooled odd ratios for sporadic Y. enterocolitica infections

\begin{tabular}{|c|c|c|c|c|c|c|c|c|}
\hline Risk Factor & $\begin{array}{l}\text { Risk factor } \\
\text { precise }\end{array}$ & Pooled OR [IC95\%] & $\mathrm{N} / \mathrm{n}^{*}$ & $\begin{array}{l}p \text {-value of } \\
\text { risk factor }\end{array}$ & OR ratios and $\mathrm{Cl} 95 \%$ & $\begin{array}{c}\text { Publicati } \\
\text { on bias } \\
\text { p-value }\end{array}$ & $\begin{array}{l}\text { Points } \\
\text { removed }\end{array}$ & $\begin{array}{l}\text { Heterogeneity } \\
\text { analysis }\end{array}$ \\
\hline \multirow{3}{*}{$\begin{array}{l}\text { Pork and other } \\
\text { meats (1) }\end{array}$} & Raw & $5.412[2.180-13.436]$ & $3 / 5$ & $<.0001$ & 4.374 [2.203 - 8.683] & \multirow{3}{*}{0.001} & \multirow{3}{*}{0} & \multirow{3}{*}{$\begin{array}{l}\text { Tau2 }=0.196 \\
Q E(d f=25)= \\
44.6561, p-v a l= \\
0.0091 \\
S 2=0.329 \\
\mid 2=37.367\end{array}$} \\
\hline & Undercooked & 4.354 [ 2.650 - 7.153] & $3 / 9$ & $<.0001$ & 3.519 [2.678 - 4.622] & & & \\
\hline & Base & $1.237[0.990-1.547]$ & $6 / 14$ & 0.062 & I & & & \\
\hline \multirow{2}{*}{$\begin{array}{l}\text { Pork and other } \\
\text { meats (2) }\end{array}$} & $\begin{array}{l}\text { Undercooked+ } \\
\text { raw }\end{array}$ & $4.215[2.657-6.684]$ & $5 / 14$ & $<.0001$ & 3.417 [2.681 - 4.355] & \multirow{2}{*}{0.001} & \multirow{2}{*}{0} & \multirow{2}{*}{$\begin{array}{l}\text { Tau2=0.037 } \\
Q E(d f=26)=44.765 \\
p-v a l=0.013 \\
S 2=0.330 \\
\mid 2=10.022\end{array}$} \\
\hline & Base & $1.233[0.991-1.534]$ & $6 / 14$ & 0.060 & l & & & \\
\hline
\end{tabular}

${ }^{*} \mathrm{~N} / \mathrm{n}$ Number of studies/number of OR;** points removed by sensitivity analysis, all results are given after removing data concerned; ${ }^{* \star *}$ Between-study variability (Tau2), test for residual heterogeneity (QE), variance of residuals $\left(\mathrm{s}^{2}\right)$, intra-class correlation $\left(\mathrm{I}^{2}\right)$. 